\title{
Teachers' Use of Technology Affordances to Contextualize and Dynamically Enrich and Extend Mathematical Problem-Solving Strategies
}

\author{
Manuel Santos-Trigo ${ }^{1}$ (D), Fernando Barrera-Mora ${ }^{2}$ and Matías Camacho-Machín ${ }^{3, *(D)}$ \\ 1 Mathematics Education Department, Centre for Research and Advanced Studies, CDMX, Avda. IPN 2508, \\ San Pedro Zacatenco 07360, Mexico; msantos@cinvestav.mx \\ 2 Physics and Mathematics Department, Autonomous University of Hidalgo State, UAEH, Carretera Pachuca \\ Tulancingo km 4.5, Colonia Carboneras, Mineral Reforma, Hidalgo 42182, Mexico; barrera@uaeh.edu.mx \\ 3 Departamento de Análisis Matemático, Facultad de Ciencias, Universidad de La Laguna, Avda. Astrofísico \\ Francisco Sánchez s/n, 38200 Santa Cruz de Tenerife, Spain \\ * Correspondence: mcamacho@ull.edu.es
}

Citation: Santos-Trigo, M.;

Barrera-Mora, F.; Camacho-Machín,

M. Teachers' Use of Technology

Affordances to Contextualize and

Dynamically Enrich and Extend

Mathematical Problem-Solving

Strategies. Mathematics 2021, 9, 793.

https://doi.org/10.3390/math9080793

Academic Editor: Marta Molina

Received: 27 January 2021

Accepted: 1 April 2021

Published: 7 April 2021

Publisher's Note: MDPI stays neutral with regard to jurisdictional claims in published maps and institutional affiliations.

Copyright: (C) 2021 by the authors. Licensee MDPI, Basel, Switzerland. This article is an open access article distributed under the terms and conditions of the Creative Commons Attribution (CC BY) license (https:/ / creativecommons.org/licenses/by/ $4.0 /)$.

\begin{abstract}
This study aims to document the extent to which the use of digital technology enhances and extends high school teachers' problem-solving strategies when framing their teaching scenarios. The participants systematically relied on online developments such as Wikipedia to contextualize problem statements or to review involved concepts. Likewise, they activated GeoGebra's affordances to construct and explore dynamic models of tasks. The Apollonius problem is used to illustrate and discuss how the participants contextualized the task and relied on technology affordances to construct and explore problems' dynamic models. As a result, they exhibited and extended the domain of several problem-solving strategies including the use of simpler cases, dragging orderly objects, measuring objects attributes, and finding loci of some objects that shaped their approached to reasoning and solve problems.
\end{abstract}

Keywords: mathematical problem solving; Apollonius problem; dynamic models; digital tools; online developments; high school teachers' reasoning

\section{Introduction}

Many curriculum proposals and learning scenarios around the world are framed and supported through problem-solving principles and activities [1]. Furthermore, there might be different ways for teachers to interpret, design, and implement a learning scenario that fosters the students' development of problem-solving competencies in learning and applying mathematical concepts [2]. " ... there cannot be any intrinsic identity for problem solving; we can only talk about the different ways that educators and other interested parties have evoked the term "problem solving," and their motives in doing this" [3] (p. 389).

Thus, to shed light on the identity and a characterization of what a problem-solving approach entails, it is important to address and discuss issues or themes regarding: (a) the types of problem and instructional activity that are actually implemented in learning environments; (b) the tools, including digital ones, that students or problem solvers use to understand concepts and to approach problems; and (c) the instructional goals that teachers aim for and pursue, including ways in which learners' problem-solving competencies are assessed $[4,5]$.

Among the multiple ways of organizing and implementing problem-solving activities, a transversal aspect that permeates any problem-solving approach is to think of and conceptualize the study of the discipline as a set of dilemmas that students need to delve into, elucidate, and solve through the use of mathematical concepts, resources (including digital affordances), and problem-solving strategies [6]. Furthermore, understanding a concept or solving a mathematical problem involves a continuous reflection process in 
which learners pose questions to dig into a concept's meaning, to construct and explore problem representations or models, to find objects' mathematical properties, and to think of distinct ways in which to solve problems [7]. That is, in a problem-solving approach, questions become a vehicle for students to delve into concepts, to represent, explore and solve tasks, and to develop and activate a mode of thinking that reflects features that are consistent with mathematical practices. Through an inquiry process, learners identify and analyze key information embedded in a mathematical situation, organize and represent data, identify patterns, formulate conjectures, and support mathematical results. Thus, to support the study, we argue that in a problem-solving scenario it is important for teachers and students to rely on the coordinated use of digital technologies and online developments to engage them in an inquiry approach in order to delve into concepts and to solve mathematical problems.

\section{Digital Technologies and Mathematical Reasoning}

Nowadays, significant developments and uses of digital technologies are shaping the ways in which people interact and communicate with others; additionally, technology's affordances are providing novel routes for learning disciplinary knowledge and for solving problems [6]. How can practicing mathematics teachers incorporate the systematic use of digital technologies in their classes? What types of technology and online platforms should they consider and consult in order to guide their students in the construction of mathematical knowledge and in solving problems? The discussion of these types of question becomes important to identify and characterize ways of reasoning and problem-solving strategies that teachers and students could develop and exhibit when they systematically rely on technology affordances to represent, explore and understand concepts and to pose and solve mathematical problems.

The use of Dynamic Geometry Systems (DGS) provides affordances for teachers/students to model or represent and explore concepts and problems dynamically [8]. In this context, dynamically modeling problems, quantifying or measuring objects' attributes (area, segment lengths, angles, etc.) and dragging or moving orderly elements within the model and finding loci of particular elements become important strategies for learners to identify, explore, and support objects' mathematical relations. Similarly, multiple purpose technologies or communication apps (FaceTime, Skype, Twitter, Zoom, Teams, etc.), provide learners with an opportunity to share and discuss mathematical ideas or problem approaches beyond class settings.

Ad hoc online platforms (https:/ / www.khanacademy.org, accessed on 17 January 2021) or encyclopedias (https:/ / en.wikipedia.org/wiki/Main_Page, accessed on 17 January 2021) also offer a variety of resources such as short videos explaining concepts or information and activities that are useful for learners to clarify and extend their mathematical knowledge about concepts and contents that they study.

In a changing society, it is important to constantly examine and ask: "What mathematics is worth teaching?" [9]. In terms of the school goals "one of the main functions of schooling today is to enable students to handle novel situations in powerful ways" [10] (p. 198). The integration and systematic use of digital technologies in teaching practices might offer an opportunity for teachers to reconceptualize their own teaching. With the use of technologies, teachers could discuss mathematical tasks, redesigning instructional paths and goals to explicitly include ways in which technology affordances could contribute to the emergence of novel routes of representing, exploring, discussing and solving mathematical tasks.

The aim of this study is to analyze and document the extent to which high school mathematics teachers relied on the use of a Dynamic Geometry System (GeoGebra) and online developments in problem-solving approaches. To this end, a set of tasks was chosen to illustrate ways in which teachers used online resources (Wikipedia) to contextualize and review concepts associated with problem situations or statements. Furthermore, the participants engaged themselves in the construction of dynamic models of tasks and 
discussed how tool's affordances shape their problem-solving approaches. This technology approach provides teachers with an opportunity to identify affordances that provide powerful ways to apply problem-solving strategies. Throughout all participants' attempts and solution processes, they were encouraged to pose and discuss questions to understand the task statements, to interpret concepts geometrically, to formulate conjectures, and to solve the tasks and communicate results. From this perspective, they had an opportunity to experience by themselves what and how the process of using digital technology contributes to their teaching practices.

\section{Essentials of a Conceptual Framework}

The conceptual framework that supports the study was structured in terms of problematizing the use of digital technology in a problem-solving approach to support and enhance mathematical learning. That is, it is important for students to engage in mathematical activities that foster questioning, critical-thinking and creative-thinking abilities in their problem-solving approaches [11]. To this end, questions that problem solvers pose and discuss during the solution episodes (understanding, plan solution, exploration, solution and task extension) are central to delve into the extent to which learners' systematic use of digital affordances permeates their ways of understanding concepts and reasoning about problems and solutions.

In this context, "to learn something, the learner must discern what is to be learned (the object of learning)" [10] (p.193). In this case, learning mathematics via problem-solving activities involves more than reporting a problem solution; it includes learners' discussion and reflection on what concepts, strategies and resources are used to understand, represent, explore, and solve problems. Thus, tasks or mathematical situations and their contexts play a crucial role in structuring and organizing learning activities in order to guide and foster the learners' construction of mathematical knowledge.

The mathematics community recognizes that the study of mathematics involves or is about posing and solving mathematical problems [12]. "Mathematics teaching has always, from the earliest human records, been based on the use of examples" [13]. What problems or tasks do students need to deal with in order to engage in mathematical thinking and reflection? Research reported that students who had successfully completed a first university calculus course showed serious difficulties in solving what they call nonroutine problems [14]. Results showed that students experienced serious difficulties in working on the tasks and nobody was able to solve any problem correctly [14]. Thus, the types of problem and ways to solve them shape the students' problem-solving behaviors.

Furthermore, they suggest that learners need to address, discuss, and solve nonroutine tasks. That is, learning mathematics is more than dealing with and solving routine tasks, it actually implies that students develop a way of thinking to continuously refine and extend their problem-solving approaches [15]. From this perspective, mathematical tasks are the vehicle for learners to engage in problem-solving activities that include representing or modeling the problems, exploring and observing behaviors with involved parameters, identifying patterns, making conjectures regarding the behaviors of object attributes, and looking for different arguments to support and validate mathematical conjectures and relations.

The way in which students work on the task is important since "the purpose of a task is to initiate mathematically fruitful activity that leads to a transformation in what learners are sensitized to notice and competent to carry out" [16] (p. 25). In this process, students/teachers should discern what attributes change or keep constant while delving into the parameters of their behavior during the process of solving tasks. Furthermore, the complexity involved during the process of learning makes it necessary to focus on activities that help learners distinguish what is necessary and important and what is contingent during problem-solving activities. Thus, questioning is a key instructional strategy to guide students in solving problems. "Questioning also elicits learners' responses, such as explaining or reasoning, to facilitate and develop higher-order thinking as they learn 
problem-solving skills" [17] (p. 276). That is, questions that students pose and pursue are not only relevant in understanding and solving tasks; but also a vehicle to delve into the students' thinking and problem-solving approaches.

The richness of a task is not determined by the task itself, but by the way in which students' approach and solve it [18]. Thus, a task should be seen by students as an opportunity and departure point to engage themselves in sense-making activities and mathematical thinking. An inquisitive or inquiring approach to deal with mathematical tasks is essential for students to explore, develop and refine their mathematical thinking [6]. Likewise, through this approach, students can transform textbook routine exercises into a set of extended and nonroutine tasks. In this process, they express their mathematical engagement through the questions that they pose and discuss in order to understand mathematical concepts and to solve problems. The use of questions and prompts becomes a tool to help learners to overcome difficulties and to direct their attention to ideas or ways to make progress or solve problems [19].

During the process of working on and solving a mathematical task, the students' knowledge or background, and the actions they undertake, shape and are shaped by the use of and interaction with technologies [20]. " ... the abundant use of digital technology does not only raise the need for skills that complement what computers (can) do, but it also influences what mathematics is or becomes relevant in our society" [21] (p. 116).

It is also relevant for teachers to discuss what and how the use of technology contributes to the students' understanding of concepts and to solving problems in teaching scenarios [22].

Polya proposed a framework to structure and organize a problem-solving approach to solving and discussing problems. It includes a set of questions that learners address through problem-solving phases that involves understanding the problem, devising a plan, carrying out the plan and looking back [23]. The use of heuristic strategies such as using auxiliary or related problems, exploring particular or simpler cases, or finding patterns, appears relevant and is emphasized throughout all problem-solving processes. The students' use and implementation of problem-solving heuristic goes hand in hand with their previous knowledge and ways to access it in their solution attempts. The use of digital technologies such as GeoGebra, in a problem-solving scenario, not only expands the scope for students to implement heuristics while exploring dynamic models of tasks, but also provides affordances to access and extend previous knowledge and mathematical results $[6,8]$.

The use of a DGS influences the students' ways of representing and exploring concepts or tasks, and as a consequence the activation of technology affordances go hand in hand with the type of questions they pose and discuss to achieve mathematical understanding and problem solutions [24,25]. In categorizing the tools, Dynamic Mathematical Technologies (DMT) are those tools with which users have an opportunity and possibility of making multiple dynamic linkages within mathematical representations to explore, understand and construct mathematical concepts [26]. These technologies are important for implementing a curriculum that embeds and supports the use of digital technologies to learn mathematics. In this perspective, there is a framework focuses on integrating curriculum, students, teachers, and teachers' professional development to discuss mathematical knowledge and pedagogy for teaching with technology [26]. Thus, mathematics pedagogical technology knowledge (MPTK) takes into account the teachers' knowledge of mathematics, their principles and strategies in organizing their teaching, including the students' mathematical knowledge, their goals, beliefs, values and teaching orientation and the process involved in students' appropriation of digital technology in learning the discipline and in solving problems. Furthermore, a conceptual framework to examine the use of GeoGebra in problem-solving activities might involve: (a) making explicit to students the potential of GeoGebra to support problem solving and reasoning; (b) identifying and supporting imitative and creative reasoning; and (c) fostering and categorizing different types of proof to support and validate conjectures [27]. 
Learners' tool appropriation goes hand in hand with both the selection of tools and ways of using technology affordances in problem-solving activities [24]. Thus, students' use of technology shapes their ways of reasoning about solving problems and understanding mathematical concepts. Hence, learners' tool appropriation involves ways in which they use technology affordances to model or represent and explore mathematical tasks. Specifically, a tool appropriation can be traced in terms of the type of question they pose and ways in which they identify patterns and relationships within the model to solve and extend initial problems.

Thus, the research question that guided the development of this study was: how could the high school teachers' technology appropriation process be characterized and how did they rely on digital technology affordances and online developments to reason and work on mathematical tasks within a problem-solving environment? Specifically, we are interested in analyzing and characterizing the extent to which the participants extend and enhance the domain and application of problem-solving strategies to construct and explore dynamic models of the tasks of identifying, exploring, and supporting mathematical relations during their tasks' solution approaches.

\section{Methodological Elements, Tasks, and Procedures}

Seven high school teachers participated in two weekly mathematical problem-solving sessions of three hours each session during one semester. The sessions correspond to a course that is part of a program for high school mathematics teachers to obtain a MSc degree in mathematics education. The participants were given the tasks in advance (previous to the formal session) and were asked to answer a series of questions related to the task contents, context, and background. The idea was that they could consult online sources to respond to the questions and also to review relevant content associated with the tasks. Participants had some experience in the use of GeoGebra since they had previously taken a course on mathematics education and technologies.

To work on the tasks, the participants were organized into two pairs and one small group of three and they initially worked on each task and later shared their work with the whole group. To present and share their work they used an "AirServer" tool to display their solution attempts to the entire class. At the end of each session, the instructor coordinated plenary discussions where a summary of problem solutions was presented. It is also important to recognize that when teachers and students work on tasks in groups or collaboratively, they not only share their ideas and listen to others, but also tend to question and argue during group presentations [28].

The pairs and the group of three participants handed in their GeoGebra files that included comments and questions they posed during the solution process. In general terms, we traced the participants' work following an adjusted path that involves: individual attempts, interaction with peer solvers and interaction with the instructor and within the class community [29]. Thus, the nature of this study is qualitative, since we are interested in documenting patterns of the participants' behaviors in the use of technology's affordances to contextualize, represent, explore and solve the tasks. The trustworthiness of this type of study is achieved through fulfilling criteria that involve prolonged engagement and persistent observation, peer debriefing, member checking, thick description, triangulation, and reflexibility [30]. In this study, the research team discussed in advance the tasks and an implementation plan that lasted one semester. That is, the team identified and analyzed mathematical resources and problem-solving strategies that are important to design an instructional route that fosters the use of technology in actual learning environments [25]. Thus, one member of the research team coordinated the problem-solving sessions and two $\mathrm{PhD}$ students participated directly in the development of the sessions. In addition, after each session, a written report, that included DGS files, was sent to and discussed within the research team.

We focus on analyzing what the participants showed when they worked on one representative task during two sessions. The task involves the construction of circles that 
are tangent to three given circles and was posed by Apollonius of Perga (late third-early second centuries $\mathrm{BC}$ ).

According to Wikipedia, many mathematicians were interested in solving and extending this problem at different times (Adriaan van Roomen, François Viéte, Isaac Newton, etc.). The resources and methods they used to approach this problem involved concepts and strategies that were important in developing areas such as analytic geometry and algebra. However, even when the statement of the problem is not difficult to understand, the methods used to solve it are complex and not easy to follow by high school students (https:/ / en.wikipedia.org/wiki/Problem_of_Apollonius, accessed on 7 January 2021). With the use of a DGS, teachers can explore a dynamic approach to this type of problem and discuss instructional routes for students to solve it geometrically. Viéte's method of solving the problem involves considering analyzing limiting cases where a point can be thought of as a circle with zero radius or a line as a circle with an infinite radius. Based on this idea, ten cases arise that involve the tangent circles to be constructed and a combination of three objects (a circle, a line, and a point) (Figure 1).

\begin{tabular}{|c|c|c|c|c|}
\hline Index $*$ & Code $\rightarrow$ & Given Elements & $\begin{array}{c}\text { Number of solutions } \\
\text { (in general) }\end{array}$ & $\begin{array}{c}\text { Example } \\
\text { (solution in pink; given objects in black) }\end{array}$ \\
\hline 1 & PPP & three points & 1 & \\
\hline 2 & LPP & one line and two points & 2 & \\
\hline 3 & LLP & two lines and a point & 2 & \\
\hline 4 & CPP & one circle and two points & 2 & \\
\hline 5 & LLL & three lines & 4 & \\
\hline 6 & CLP & one circle, one line, and a point & 4 & \\
\hline 7 & CCP & two circles and a point & 4 & \\
\hline 8 & CLL & one circle and two lines & 8 & \\
\hline 9 & CCL & two circles and a line & 8 & \\
\hline 10 & $\operatorname{ccc}$ & three circles (the classic problem) & 8 & \\
\hline
\end{tabular}

Figure 1. Ten cases of Apollonius' problem (P-point, L-line, C-circle) (https://en.wikipedia.org/wiki/Problem_of_ Apollonius, accessed on 19 January 2021).

The first goal for the participants was to consult online resources related to the problem. In this case, the instructor oriented the participants on what information they needed to search and examine regarding the problem. To achieve this goal, a set of questions 
was posed to the participants: what does the Apollonius problem involve in terms of mathematical objects and goals? Why is this problem relevant? What types of solution have been identified throughout history? What about examining and solving the ten cases that involve a combination of a circle, line, and a point? What essential properties of these objects are important in constructing a dynamic model to solve each case? What problem-solving strategies, concepts, and mathematical properties of involved objects are important to discuss in order to represent and solve the problems? The participants shared their responses to some of these questions via a digital wall (Padlet) and the main ideas were discussed during the corresponding sessions. Other questions were addressed when they actually worked on the task.

\section{Presentation of Results}

Results of the study are structured and presented around the participants' process involved in selecting and using online information to work on the task, including the identification of simpler cases, as a strategy to address the problem. Likewise, the analysis of results includes a characterization of the ways of reasoning that the participants, as a group, exhibited during the development of the sessions (research question). That is, the goal is to present and discuss the extent that the participants relied on technologies' affordances and online developments to work on the tasks and extend their problem-solving approaches. The main source of data came from students' GeoGebra files and written reports that they presented to the class and were reviewed after plenary discussions. The research team analyzed the participants' approaches to the task and provided continuous feedback during the group discussions. Thus, the presentation of results is organized in terms of problem-solving episodes [15,31] associated with the participants' construction and exploration of dynamic models that emerged during the sessions.

I. The context of the task, trend solutions, and the use of online developments.

The participants worked on the Apollonius task in pairs (two pairs: A \& B) and a group of three $(\mathrm{C})$ initially during the session, and later they shared and discussed their work within the whole group. Table 1 shows what online sources pairs A \& B and group C consulted and the questions they addressed in their written report (essay).

Table 1. Topics addressed by the participants in their essay on the Apollonius problem.

\begin{tabular}{cccc}
\hline Participants & Resources & Topic & Main Ideas \\
\hline Pair A & Wikipedia, YouTube & $\begin{array}{c}\text { Apollonius' problem and } \\
\text { Treatise on Conic sections }\end{array}$ & $\begin{array}{c}\text { Definition of conic sections, the importance } \\
\text { of focusing on simpler problems. }\end{array}$ \\
\hline Pair B & Wikipedia, Khanacademy & $\begin{array}{c}\text { Apollonius' problem, } \\
\text { Hellenistic period }\end{array}$ & $\begin{array}{c}\text { The context of the problem and the } \\
\text { Greek period. }\end{array}$ \\
\hline Group C & Wikipedia, Woframalpha & Apollonius life and problems & $\begin{array}{c}\text { Methods for solving the Apollonius problem } \\
\text { and the construction of dynamic models of } \\
\text { simpler cases }\end{array}$ \\
\hline
\end{tabular}

Wikipedia (https:/ / en.wikipedia.org/wiki/Apollonius_of_Perga, accessed on 22 January 2021) was the main source that the participants consulted to know about who Apollonius of Perga was, and about the context of Apollonius' problem (https://en.wikipedia. org/wiki/Problem_of_Apollonius, accessed on 3 January 2021). Thus, the participants handed in a written report in which they included some biographical information:

For example, a pair of teachers reported: "Apollonius lived at the end of 3rd and beginning of 2 nd centuries (c. 262 BC-c. 190 BC) and his main interest and contributions were in Astronomy and Geometry in particular the study of the conic sections. Apollonius lived at the end of what was known as the Hellenistic period in which he contributed to the development of geometry influenced by the work of Euclid".

Figure 1 shows the ten cases of the Apollonius problem taken from Wikipedia. These cases helped the participants focus on simpler problems as a way to identify and un- 
derstand the geometric meaning of essential concepts to approach the problem. Indeed, they recognized that the information provided by Wikipedia was useful to contextualize the problem and to review methods and historical approaches to solve it. Here, they all recognized that Wikipedia offers relevant information both to conceptualize problems and to review or extend knowledge related to concepts involved in problem statements. Indeed, the cases shown in Figure 1 led them to think of the problem in terms of approaching simpler cases as a way to address the general case.

Some participants also reported on the importance of Apollonius' problem in terms of the methods used to solve it [32]. As a result, the solution attempts contributed to the developments of results in areas such as analytic geometry and calculus. In this review, Cartesian and synthetic approaches to the problem are discussed.

One pair, during its presentation, referred to the work on models and modeling regarding the importance of contextualizing problem situations [33]. This perspective recognizes the importance of engaging students in "warm-up activities" that provide a context to the task, as an initial or previous stage for them to work on model-eliciting activities [34].

“... Often they (warm-up activities) are based on a math-rich newspaper article, or on a math-rich web site, which is followed by a half dozen questions aimed at helping students read with a mathematical eye while also familiarizing them with the context of the model-eliciting activity" [34] (pp. 45-46).

In reviewing the problem of Apollonius, the participants identified and discussed ideas and concepts used to construct "circles that are tangent to three given circles" and found out that this problem had been solved through methods that involve algebraic and geometric approaches. In particular, Viéte's solution involved the exploration of limiting cases. That is, the idea was to think of one point as a circle of radius zero and a line as a circle of infinite radius. Based on this idea, ten combinations of three objects (point, circle and line) are generated and represent special cases of the Apollonius problem (Figure 1).

During the plenary discussion, the participants recognized that Viéte's idea of using limiting cases is a key strategy to reduce the complexity of the problem and to focus on simpler cases to solve it. In general, the participants pointed out that the Wikipedia information was important to contextualize the problem and also to think of the problem in terms of solving particular cases. Thus, Figure 1 not only helped them think of the task in terms of simpler cases, but also the use of GeoGebra became important to connect, reconsider, and apply methods used to solve those cases in order to approach the Apollonius problem. The use of GeoGebra fosters active students' participation in problem-solving activities and enhances interaction and collaboration between students and their teacher and between students [35].

II. The use of GeoGebra and focusing on simpler cases.

Based on what the participants read and wrote in their essay about Apollonius problem, all the group decided to work on some simpler cases following Viéte's strategy of thinking of three circles in terms of a point, a line, and a circle (Figure 1). Here, we present what the participants showed while working on two simpler cases that they had addressed within the previous class to solve the given task of constructing circles tangent to three given circles. To this end, we focus on identifying the questions posed by the group during the plenary sessions, ways of delving into those questions and what problem-solving strategies were important to work on the task. We emphasize ways in which the participants relied on the tool's affordances to move objects within the dynamic task representation in order to identify and explore the mathematical relations that led them to solve the tasks.

Table 2 shows the main ideas that led pairs A \& B and group $C$ to construct a dynamic model of simpler cases associated with the Apollonius problem. 
Table 2. Examples of participants' dynamic models of the tasks.

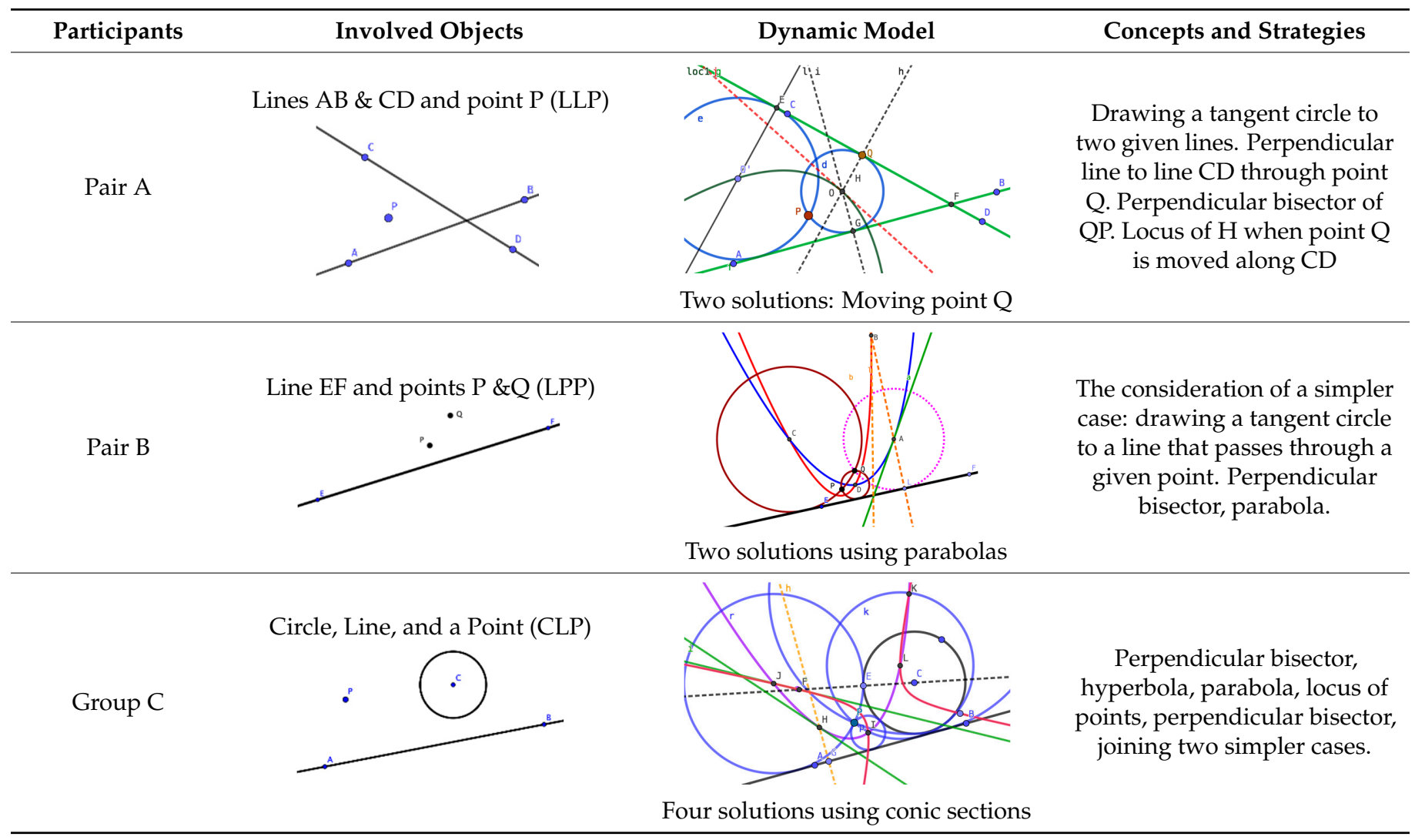

The pairs and the small group shared and discussed their group work on the simpler cases with the whole group. We used GeoGebra command "Construction Protocol" to present ways in which the participants reasoned about the task. It is also shown how they relied on technology affordances to build up a dynamic model for each simpler case. Thus, we focus on the presentation of two initial cases (LPP and CLP) that led the participants to solve the general case of the Apollonius problem. Here, we present essential episodes that participants showed in their construction protocol to approach each case and then we comment on their ways of reasoning about solving each case.

II.1a. A case that involves two given points and a line. Figure 2 shows the two given points $P \& Q$ and a given line EF. Then, the goal is to construct a tangent circle to line EF that passes through points $P \& Q$ (LPP in Figure 1).

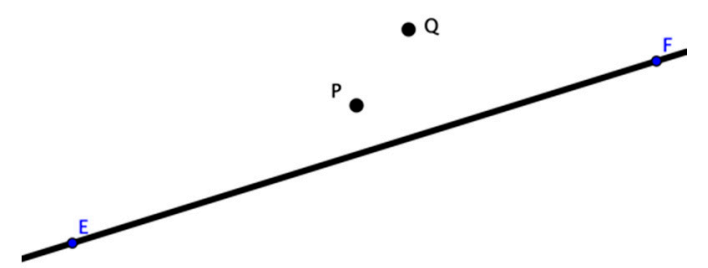

Figure 2. How to construct a tangent circle to line EF that passes through point $\mathrm{P} \& \mathrm{Q}$ ?

The two pairs and group $C$ focused on a simpler case that involved constructing a tangent circle to line EF that passes only through point $Q$ instead of considering both points. A question posed by one of the participants was: where should the center of a tangent circle to line EF be located? Initially, pairs A \& B recognized that the center of a tangent circle to a given line must lie on the perpendicular line through the tangency point (Figure 3). 


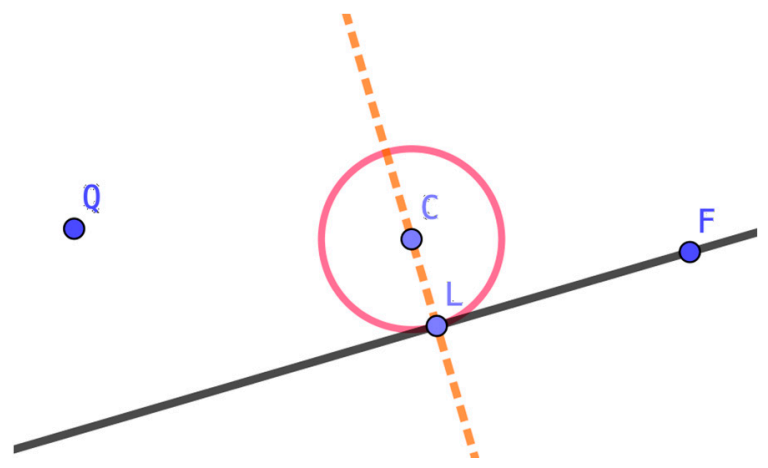

Figure 3. The center $\mathrm{C}$ of a tangent circle to a given line lies on the perpendicular to the line at the tangency point L.

One of the participants asked: Is there a position for $\mathrm{C}$ on the perpendicular line, so that the tangent circle to EF passes through point $\mathrm{Q}$ ? To answer this question, they moved point $\mathrm{C}$ along the perpendicular to $\mathrm{EF}$ at $\mathrm{L}$ and observed that satisfying this condition implies that the distance CQ must be equal to distance CL. That is, the center C must be located at the intersection of the perpendicular bisector of LQ and the perpendicular line to the given line at L (point A) (Figure 4). It is observed that partial goals were achieved through geometric properties of the involved objects.

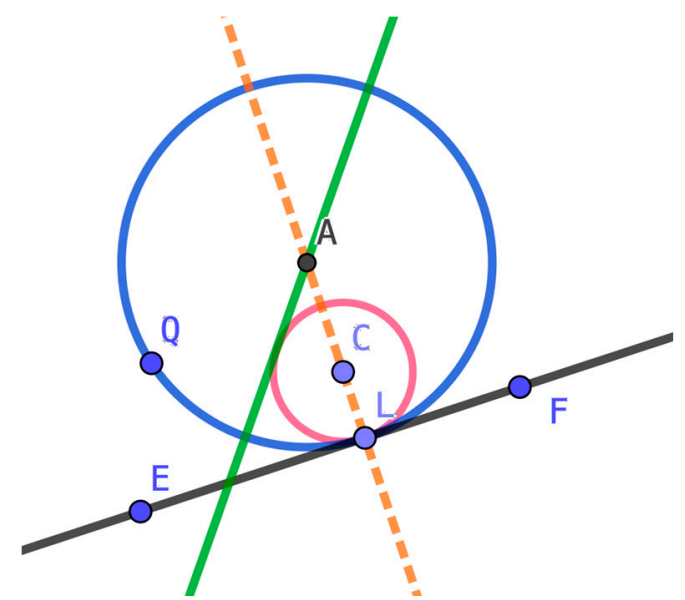

Figure 4. The intersection of the perpendicular bisector of $\mathrm{QL}$ and the perpendicular to $\mathrm{EF}$ at $\mathrm{L}$ is the center of the tangency circle to $L$ that passes through point $Q$.

In Figure 4, point $\mathrm{L}$ can be moved along line EF; then it is important to explore what happens to point $\mathrm{A}$ (center of the tangent circle) when point $\mathrm{L}$ moves along line EF. That is, what is the locus of point $\mathrm{A}$ when point $\mathrm{L}$ is moved along line EF? Figure 5 shows the locus traced by point $\mathrm{A}$ and the participants mentioned that it was a parabola. Why or how do you know that the locus is a parabola? To respond to this question posed by the instructor, some participants argued that point $A$ is on the perpendicular bisector of $L Q$, then $d(A, Q)$ is equal to $d(A, L)$ (definition of parabola). That is, line EF is the directrix of the parabola and $\mathrm{Q}$ is its corresponding focus. Thus, any point on this parabola is the center of a circle that is tangent to line EF and that passes through point $Q$ (Figure 5). 


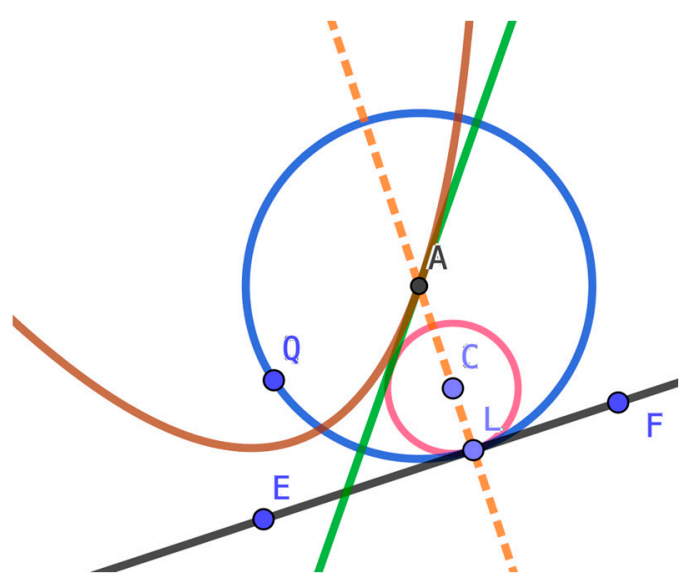

Figure 5. Any point on the locus can be the center of the tangent circle to EF that passes through point Q.

Likewise, the participants repeated the same procedure of drawing the tangent circle to line EF that now passes through point $P$. That is, they drew the perpendicular bisector (b) of segment LP and point B is the intersection of line 1 (perpendicular to EF that passes through $\mathrm{L}$ ) and line $\mathrm{b}$. The locus of point $\mathrm{B}$ when point $\mathrm{L}$ is moved along line EF is also a parabola. The intersection points $(C \& D)$ of the parabolas are the centers of circles that are tangent to line EF and pass through points P \& Q (Figure 6). They also observed that for the case in which $P \& Q$ are in different half planes determined by line EF, then the problem has no solution. It is observed that working on a simpler case, one point and a line, led the participants to solve the case LPP.

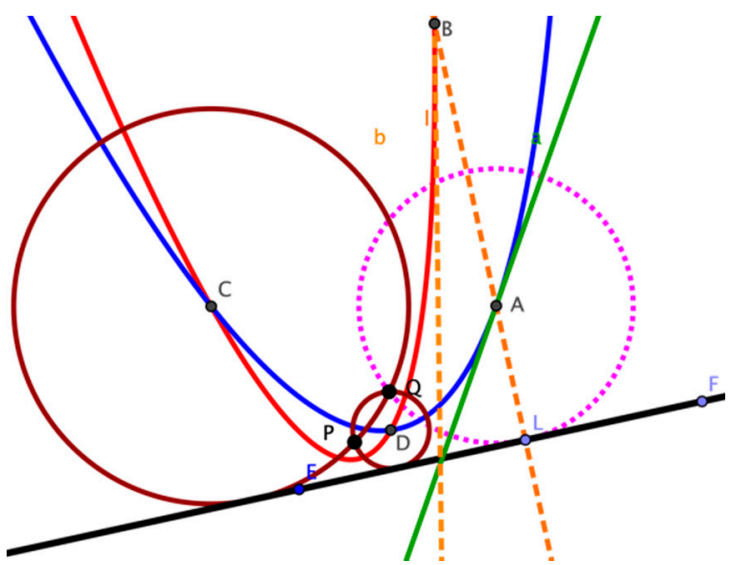

Figure 6. The loci of points A \& B when point $\mathrm{L}$ is moved along line EF are parabolas that intersect at the centers of tangent circles to line EF and pass through points P \& Q (https: / / www.geogebra.org/ $\mathrm{m} /$ vycaymhz, accessed on 18 January 2021).

II.1b. At this stage, the instructor asked: Is there another way to draw a tangent circle(s) to line EF that passes through points P \& Q (the given points)? This question led group C to focus on drawing the perpendicular bisector of PQ (line g) (Figure 7). Then the group chose any point $S$ on $g$ and drew a circle with center at $S$ and radius SP or SQ. Here, the group drew line $h$ perpendicular to line EF that passes through point $S$. Point $G$ is the intersection point of line $h$ and the circle with center at $S$ and radius SP. The group recognized that the locus of point $G$ when point $S$ is moved along line $g$ looked like a hyperbola and point $M$ is the intersection point between the locus and line EF. The perpendicular line to EF that passes through $\mathrm{M}$ intersects the perpendicular bisector of $\mathrm{PQ}(\mathrm{g})$ at $\mathrm{O}$. The circle with center $\mathrm{O}$ and radius OP is the solution to the problem (Figure 7). In the group presentation of this approach, the participants addressed issues such as: why is the locus a hyperbola? Is there 
any condition for the position of $\mathrm{P} \& \mathrm{C}$ to draw the circle using this approach? Can this approach be applied when $\mathrm{PC}$ is parallel or perpendicular to AB?

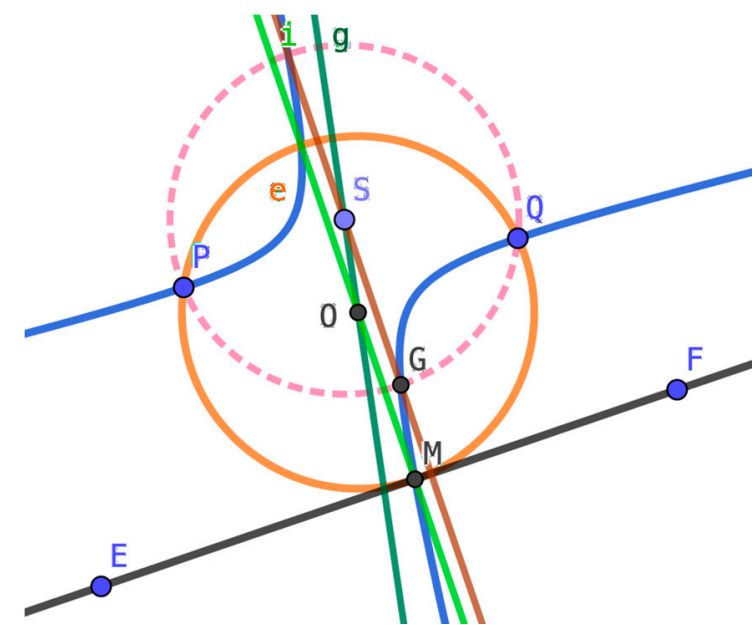

Figure 7. Finding the center of the tangent circle to line EF that passes through points $P \& Q$ (https:/ / www.geogebra.org/m/cunnsdav, accessed on 2 January 2021).

Comment: Focusing on a simpler case, with the use of GeoGebra, became a powerful strategy for the participants to solve the problem. In the first approach drawing a tangent circle to the given line that passes through one of the given points shed light on the solution. Similarly, in the second approach, drawing the circle with center at the perpendicular bisector of segment PC provided a path to solve the problem. In both approaches, the geometric meaning of what is needed to fulfill partial conditions of the problem provided directions to think of a route to achieve the solution. In this process, a conic section emerged as an important object at which the center of the wanted circle was located. Here, there is evidence that the participants relied on technology affordances to think of the problem in terms of properties and geometric meaning in order to represent and solve the task. Thus, connecting the first approach to the second case involves a certain level of the participants' tool appropriation. That is, working on simpler cases was a key strategy that helped them to solve this case. In this process, there is evidence that they relied on GeoGebra affordances to explore model properties (instrumental exploration) that were relevant to identify mathematical relations (instrumental symbiosis) to solve the problem [22].

II.2. Another special case of the Apollonius problem approached by the participants involves a circle, a line, and a point (CLP in Figure 1) and the goal was to draw a tangent circle to the given line $(\mathrm{AB})$ and to the circle $(\mathrm{C})$ that also passes through the given point $(\mathrm{P})$ (Figure 8).

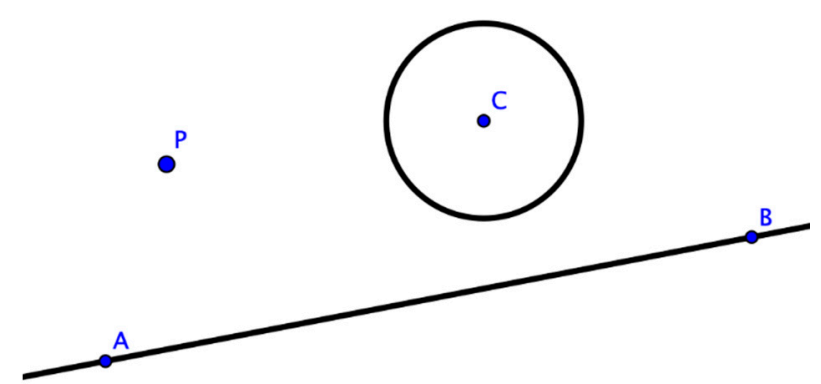

Figure 8. How to draw a tangent circle to line $A B$ and to circle with center $C$ and that passes through point P?

Group $C$ worked again on two simpler cases: One that focused on drawing a tangent circle to the given circle that passes through point $\mathrm{P}$, and the second case, that they had 
already worked out previously, which involves drawing a circle that passes through point $\mathrm{P}$ and is tangent to line $\mathrm{AB}$.

II.2a. To approach the first case, the group chose any point $\mathrm{E}$ on the given circle with center at $C$ and drew line $C E$ (Figure 9). Then they drew the perpendicular bisector of segment $\mathrm{EP}$ and identified point $\mathrm{F}$ as the intersection point of the perpendicular bisector of $\mathrm{EP}$ and line EC. Here, this group traced the locus of point $\mathrm{F}$ when point $\mathrm{E}$ is moved along the circle and argued that such locus was a hyperbola. Furthermore, using the previous construction that was used to solve the previous case (II.1a), the locus of point $\mathrm{H}$ (the intersection of the perpendicular bisector of AP and perpendicular line g) when point $G$ is moved along line $\mathrm{AB}$ is a parabola (Figure 9).

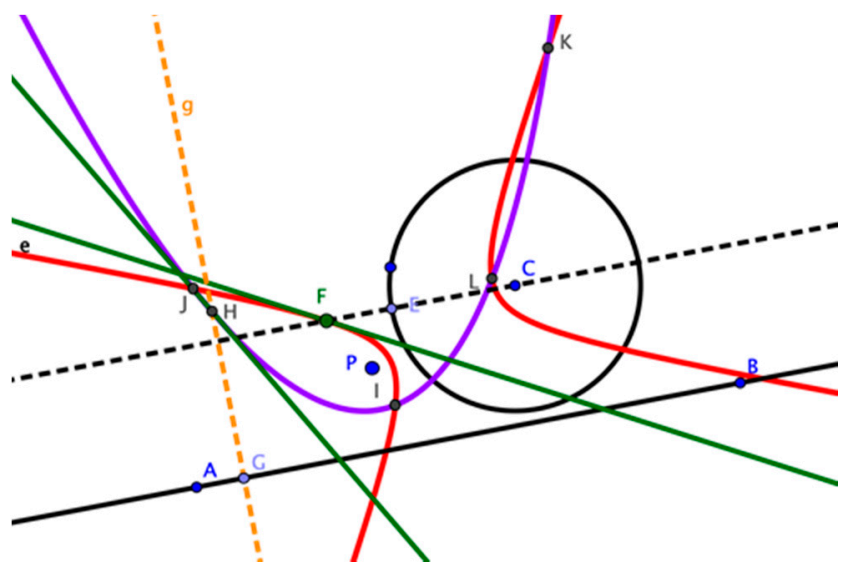

Figure 9. The loci of points $\mathrm{F}$ and $\mathrm{H}$ are conic sections.

Based on Figure 9, the intersection points of the hyperbola and parabola (I, J, K \& L) are the centers of circles that meet the problem conditions with radii IP, JP, KP \& LP, respectively (Figure 10).

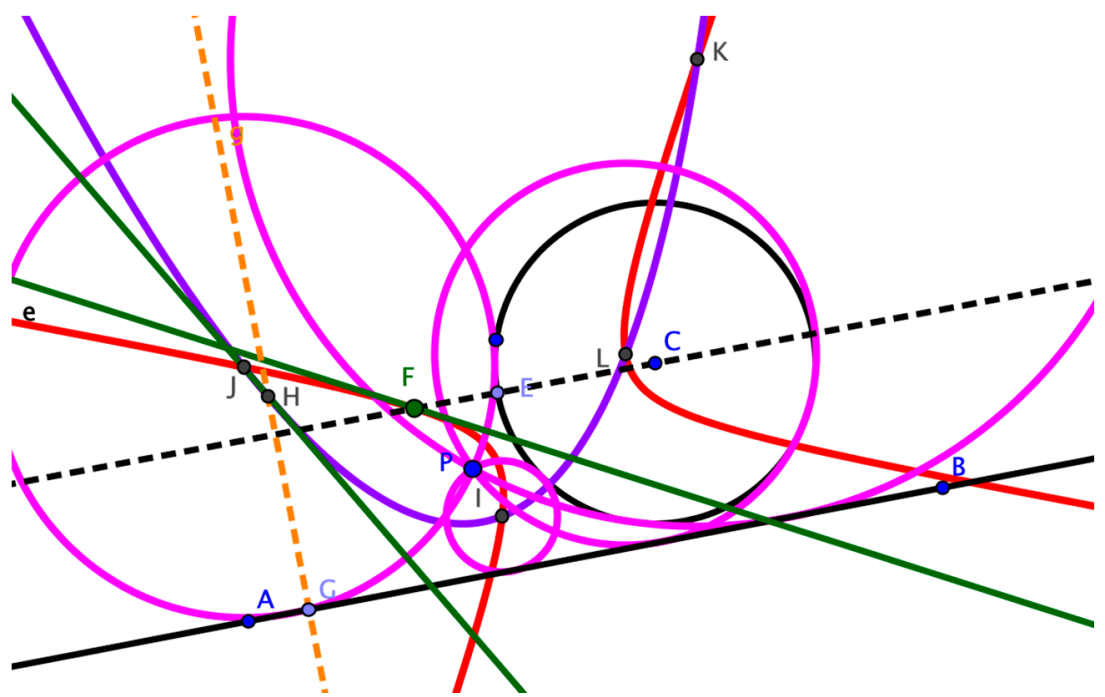

Figure 10. Drawing four tangent circles that solve the problem (https:/ /www.geogebra.org/m/xkf9 g6xs, accessed on 2 January 2021).

Comment: The consideration of the limit case (zero and infinity radii of circles) led the participants to focus on one circle, one point, and one line to approach the Apollonius problem. Furthermore, the dynamic model associated with the cases (LPP \& CLP) was constructed by implementing a problem-solving strategy that involves simplifying each case to solve for LP in the first case and CL in the second one. In the first case, drawing a 
tangent circle to a line led them to identify a parabola whose points were centers of tangent circles to the given line and that pass through the given point $(\mathrm{Q})$. Thus, the consideration of the two given points led the participants to generate two parabolas whose intersection points were the centers of the tangent circles to the given line that now pass through both given points. Similarly, splitting in two cases CL \& LP led them to generate two conic sections (a hyperbola and a parabola) whose intersections became the centers of the four circles that solve the Apollonius problem. Again, the conic sections were generated as a result of moving particular points within the representation and were crucial to solving the task. At this stage, the participants not only relied on the tool affordances to represent the tasks, but also to find relations, as the conic sections, to solve the tasks. These cases show that the participants were using the DGS affordances as a tool to represent and solve the tasks.

During the pairs and group presentations of their work, all recognized that cases LPP \& CLP provide enough information to approach the general case that involves three circles. That is, they initially considered the subgoal of drawing tangent circles to two circles, instead of three. Thus, members of Group C led the group discussion to work on the Apollonius problem.

II.3. The construction of tangent circles to three given circles. This case is the initial problem of Apollonius (CCC) (Figure 11), whose goal is to draw tangent circles to three given circles.

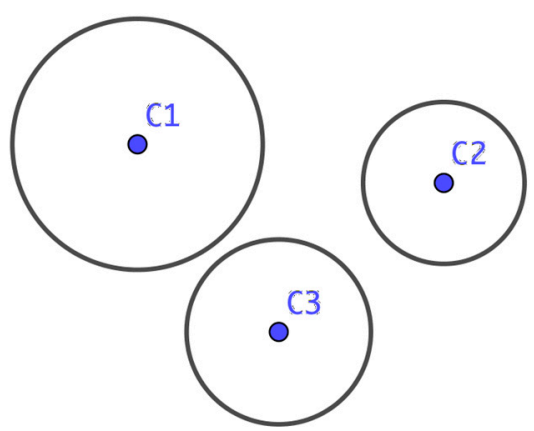

Figure 11. How to draw tangent circles to three given circles.

At this stage, the participants recognized that they have developed a method to solve this case based on what they did previously in cases II.1a,b \& II.2a. Again, the problemsolving strategy was to reduce and solve the task for simpler cases. That is, they focused on the construction of tangent circles to two given circles instead of three. In Figure 12 the circles with centers at $\mathrm{C} 1 \& \mathrm{C} 2$ are the given circles. Then, they chose point $\mathrm{G}$ (any point) on the circle with center $\mathrm{C} 1$ and drew line $\mathrm{C} 1 \mathrm{G}$. Point $\mathrm{H}$ is on a circle with center at $\mathrm{C} 2$. Line $g$ is the perpendicular bisector of segment $\mathrm{GH}$ and point $\mathrm{P}$ is the intersection of this perpendicular bisector with line $\mathrm{C} 1 \mathrm{G}$. The locus of point $\mathrm{P}$ when point $\mathrm{G}$ is moved along the circle with center $\mathrm{C} 1$ is a hyperbola. Line $\mathrm{C} 2 \mathrm{H}$ intersects hyperbola $\mathrm{k}$ at point $\mathrm{Q}$ and $\mathrm{K}$ and loci of point $\mathrm{Q} \& \mathrm{~K}$ when point $\mathrm{H}$ is moved along a circle with center $\mathrm{C} 2$ are also hyperbolas. Here, circles with centers at $\mathrm{K}$ and $\mathrm{Q}$ and radii $\mathrm{KH} \& \mathrm{QH}$ are tangent to both circles (the solution).

The way to construct tangent circles to three given circles involves applying the previous method for two circles to circles with centers at $\mathrm{C} 3$ and $\mathrm{C} 2$ and circles with centers at $\mathrm{C} 3$ and $\mathrm{C} 1$, respectively (Figure 13). There are eight tangent circles to the given circles. The participants acknowledged that the number of solutions depends upon the relative position of the given circles. Here, they explored other cases that included two of the three circles intersecting, and two of the circles tangent to each other. 


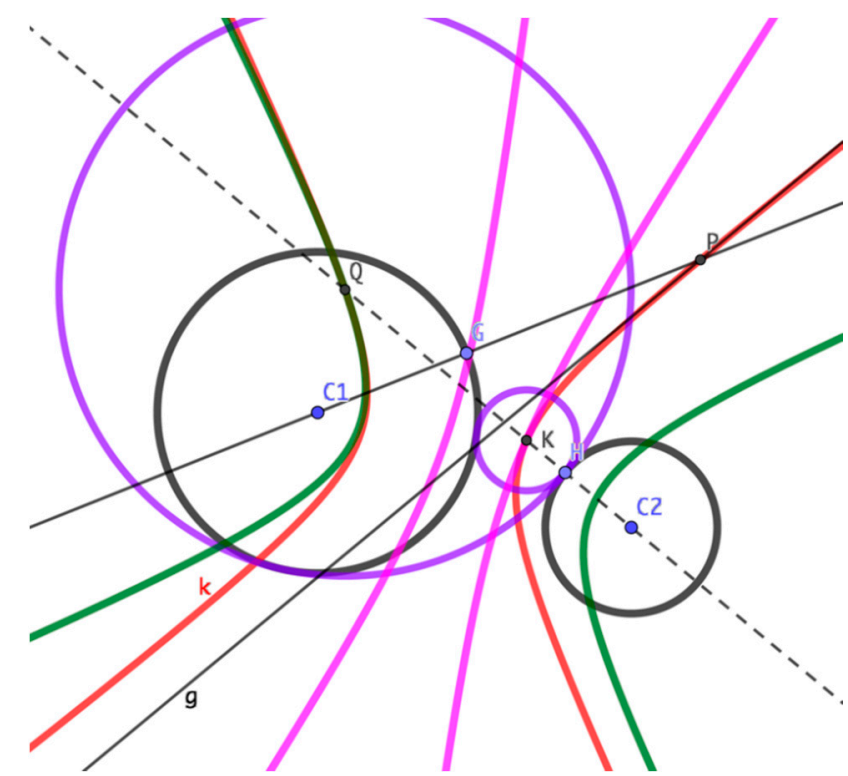

Figure 12. Drawing tangent circles to two given circles.

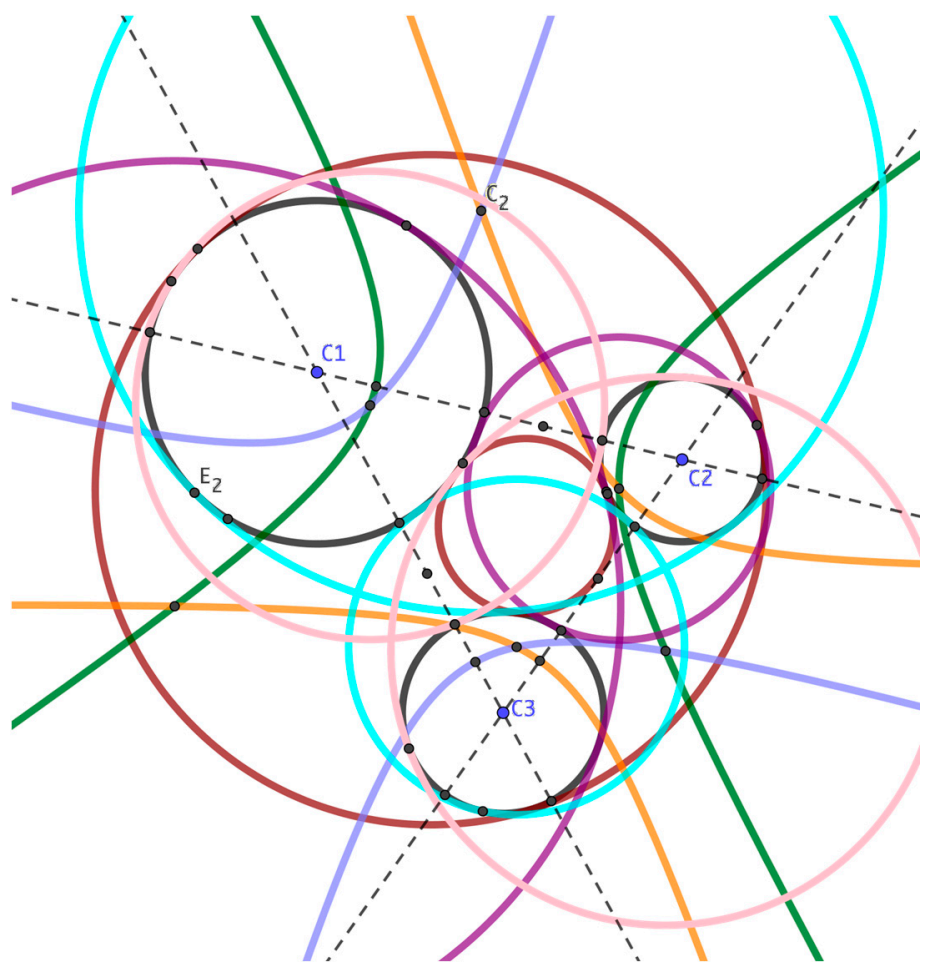

Figure 13. Drawing eight tangent circles to three given circles (https://www.geogebra.org/m/vmd8 s4xs, accessed on 3 January 2021).

Comment: Viéte's strategy of considering limiting cases of involved objects not only helped the participants to reduce the complexity of approaching the problem via traditional methods, but also provided a path to focus on special cases of the task. In this process, the dynamic model associated with each case was constructed in terms of geometric meaning of the involved concepts and was useful to solve each case. Thinking of both approaches, as a whole, provided the route and method to solve the task. In terms of the participants' tool appropriation, there is evidence that approaching the simpler cases dynamically demanded that they thought of both cases through the tool's affordances and they recognized and 
applied the methods and strategies they used in those cases to solve the general Apollonius problem (Figure 13).

\section{Discussion of Results}

There is evidence that the construction and exploration of a dynamic model of the task provided an opportunity for the participants to discern what attributes of the task representation vary or are invariant when particular objects are moved within the model [24]. Focusing on a simpler case (Figure 3) (how can we draw a tangent circle to a line?) led the participants to recognize that the center of any tangent circle to the line lies on a perpendicular to that line and the intersection of such perpendicular and the line is the tangency point (Figure 4). The concepts of perpendicular line to EF at any point (L on EF) and the perpendicular bisector of segment QL provided the information and support to find the center of the tangent circle. In addition, the tool affordance that allows moving point $\mathrm{L}$ led the participants to identify that the loci of the center of the tangent circle was a parabola. They argued that, since the center was located on the perpendicular bisector, then the distance from the center to point $\mathrm{Q}$ and to line $\mathrm{EF}$ was the same and this property corresponds to the definition of a parabola. Similarly, they applied the same strategy to draw the tangent circle to line EF and that passes through point $\mathrm{P}$ which led them to identify a second parabola. Thus, the intersection points of those parabolas are the centers of the tangent circles that solve this case (Figure 6). In terms of ways of reasoning, looking at the behavior of elements within the representation was important for the participants to find important mathematical objects (parabolas) to solve the task.

At this stage, the participants recognized that this method could be used to work on the other Apollonius cases. Indeed, the case that involves a circle, a point, and a line (Figure 8) was approached by addressing two simpler cases: (1) The construction of tangent circles to a given circle that passes through the given point, and (2) the construction of the tangent circles to the given line and that passes through the given point. To this end, they found that for the first case the locus of the centers of the circles that are tangent to the circle and pass through the given point is a hyperbola. In this case, they argued that the center (point $\mathrm{F}$ ) that generated the locus lies on the perpendicular bisector of segment $P E$ and therefore $d(C, F)-d(F, P)=d(C, E)$ which is a constant and therefore the locus represents a hyperbola with foci point $\mathrm{C}$ and $\mathrm{P}$ (Figure 9 ).

The previous cases were discussed in the plenary sessions within the group and the participants recognized that solving simpler cases, with the use of GeoGebra, was a powerful strategy to solve the problems. Indeed, representing simpler cases dynamically allowed the participants not only identifying behaviors and relations of involved objects, but also exploring properties that were useful to solve partial and global cases. In this context, they pointed out that the dynamic exploration of the objects behaviors within the dynamic model led them to identify objects such as the parabola and hyperbola that were crucial to solve the tasks. Similarly, they noticed that the perpendicular bisector, a concept that is studied in elementary school, appears in both solution processes as a key element associated with the generation of conic sections. Indeed, the argument they presented to support that both objects satisfy or hold properties of conic sections (parabola and hyperbola) was based mainly on properties of the perpendicular bisector. That is, the concept of a perpendicular bisector was instrumental to achieve the solution via the use of a DGS.

Furthermore, solving the case that involves drawing tangent circles to three given circles (Figure 13) became an opportunity for the participants to apply the method and strategy that they had used previously. Again focusing on the construction of tangent circles to a pair of given circles (Figure 12), to solve the task participants just repeated or applied the partial solution to the pair of two circles. In this case, the hyperbola that appears in case B (Figure 12) was the conic section that led them to find the centers of the eight tangent circles to the three given circles (Figure 13). They also acknowledged that the number of solutions depends on the position of the circles. 
The initial part of the session that involved discussing the questions related to the background and context of the problem of Apollonius increased the participants' interest in knowing about Apollonius' life and his achievements. In terms of the methods and strategies that people interested in this problem showed in their solutions, the participants found that algebraic approaches were common methods to solve the Apollonius problem. Indeed, they found that the Descartes' theorem [36] (p. 5) that involves three given mutual tangent circles, in which the goal is to find the radius of a four tangent circles, can also be approached following the strategies and methods used for the Apollonius case.

In terms of the research question, the results in this study showed that the use of online developments, such as Wikipedia, provides useful information to both contextualize and enhance problem statements as well as to review and extend the understanding of the concepts involved and, in some cases, to analyze previous solutions. Likewise, participants recognized the importance of problematizing the online information as a means to focus on elements that are meaningful in comprehending the problem situation. Indeed, consulting and analyzing information regarding the Apollonius problem increased the participants' interest in researching and assessing the impact of this type of problem in the development of analytic geometry (a subject that is studied at high school level). Furthermore, the participants' systematic use of GeoGebra affordances contributed to thinking about the tasks in terms of the geometric meaning of the concepts involved. Based on this geometric interpretation, they relied on problem-solving strategies (a limiting case, considering simpler cases, assuming the problem to be solved, etc.) to dynamically model the situation. This model, then, was explored via technology affordances (dragging objects, measuring attributes, tracing loci, etc.) to find patterns and relationships among objects' attributes that eventually were crucial in solving both particular cases and the task. Throughout the presentation of results, there is evidence that the participants developed a way of reasoning that included empirical, visual, graphic and functional approaches to solve the tasks. That is, the participants relied on technology affordances to integrate and implement different problem-solving strategies in the process of dealing with a geometric problem. In their approaches to the task, they showed tactical and strategic decisions. First, selecting a plan in which they consulted online resources to contextualize the problem was important for them in order to think of the task in terms of considering simpler and limiting cases (tactical decision). Second, the construction of the corresponding dynamic model of some particular cases not only was important to solve those cases geometrically, but also to figure out a method with which to solve the general case (three circles).

\section{Instructional Implications}

Two intertwined issues appear in the development of this study, (a) one that involves the selection and use of online developments or resources for teachers/students to consult in order to clarify and extend concepts or to get information regarding a task's context; and (b) another aspect related to the coordinated use of technology affordances to represent and work on mathematical tasks or problems. In terms of instructional activities, both aspects recognize the importance for students to pose questions as a means to select and examine online resources to make sense of concepts involved in problem situations. To this end, the participants acknowledged the importance of guiding learners to focus on activities that helped them identify, contrast or extend their previous knowledge about concepts involved in the given problems. From this perspective, students are encouraged to consult selected online resources to know and discuss contextual information about the problem.

It has been recognized the importance of students reading and discussing information regarding the context of the task as an introduction or background previous to engage them in solving the task [33]. A newspaper article or a historical episode is often included in the introduction of the problem statement where students read about the context and the importance of solving it. In this study, the research team chose the entry that appears in Wikipedia regarding the Apollonius problem and the participants answered a set of questions as a way to delve into the context. The participants relied on mobile devices 
(tablets or smartphones) or computers to review the entry, answer and share their responses via an online wall (Padlet).

In this study, the consideration of a simpler problem was a crucial strategy that the participants used to activate technology affordances to represent, explore, and solve the tasks. Although, the importance of looking at simpler cases to reduce the complexity of a problem has been acknowledged in problem-solving approaches [23], the use of the tool, in this case, extends the domain of exploration of this strategy in order to visualize patterns and relationship of involved attributes. Thus, the construction of a dynamic model of the cases that involved the consideration of less objects (Figure 3) (one point instead of two points and one line) not only became important for the participants to develop experiences on the use and appropriation of tools, but also the exploration of dynamic model helped the participants focus on the activation of particular affordances and strategies (dragging objects, quantification of attributes, tracing loci, using sliders, etc.) to analyze objects' invariants, and to formulate and support conjectures. In general terms, the instructional strategies that involve the use of the tool include:

(a). The construction of a dynamic model of the problem. The goal is that teachers and students rely on technology affordances to construct a model of the situation or problem. Within this model, they can move or drag orderly objects with the idea of observing behaviors of some objects' attributes in order to detect invariants or patterns associated with those attributes. The use of GeoGebra allows problem solvers to move objects continuously and observe an immediate effect or change in their attributes' behaviors [37]. In this study, the participants observed that the initial objects (point, circle or line) represent, indeed, an object family since they can be moved to different positions or change the length of the initial radius to show and analyze different arrangements. This stage is important for learners since they can pass or transit from analyzing properties of a particular case to the consideration and analysis of a family that represents those cases.

(b). The importance of searching mathematical relations. The purpose in moving objects within the model is to identify patterns and formulate conjectures regarding mathematical properties or relationships among objects' attributes. The process involved in the formulation of relations might be achieved by problem solvers through getting and analyzing information that comes from measuring length of segments, angles, registering areas, perimeters, slopes, etc. and using affordances to trace loci of attributes, define relations or functions through points, or using a table to organize data.

(c). The presentation of conjectures demands that subjects develop a language and notation to communicate and express them. For example, in tracing the locus of point A when point $\mathrm{L}$ is moved along line $\mathrm{EF}$, they conjectured initially that such a locus was a parabola. Then, they explored empirically, by measuring distances, AL \& AQ, that these distances were the same for any position of point L on EF. Thus, they identified point $\mathrm{Q}$ as the focus and line EF as the directrix of the parabola.

(d). The transition from an empirical and a visual approach in formulating and supporting conjectures to the use of geometric or algebraic arguments. In general, dynamic models of problems maintain structural properties when main objects are moved or enlarged/shorted within the model. Then, it is common that changing the dimensions or positions of some objects contributes to the process of validating a conjecture. Furthermore, the geometric analysis often provides formal arguments to validate conjectures. For example, in Figure 9, point $F$ (the point that generates the locus) lies on the perpendicular bisector of $\mathrm{PE}$ and therefore, $\mathrm{d}(\mathrm{F}, \mathrm{P})=\mathrm{d}(\mathrm{F}, \mathrm{E})$. Likewise, $\mathrm{d}(\mathrm{F}, \mathrm{C})-$ $\mathrm{d}(\mathrm{F}, \mathrm{P})=\mathrm{d}(\mathrm{E}, \mathrm{C})$ which is always constant. Then, the locus generated by point $\mathrm{F}$ when point $\mathrm{E}$ is moved along a circle with center $\mathrm{C}$ is a hyperbola whose foci are points $\mathrm{P} \&$ C. This geometric argument, although inspired and initially conjectured empirically, does not depend on measuring and moving objects within the configuration; it relies on the use of geometric properties of the involved objects. 


\section{Concluding Remarks}

The participants' work shown throughout the problem-solving sessions provides important information to characterize their ways of reasoning, associated with the coordinated use of digital technologies and online developments to represent, explore, and solve the tasks. First, the construction of dynamic models of the tasks demanded that the participants examined and interpreted the statement of the tasks geometrically. For example, drawing a tangent circle to a line led the participants to think of the position of the center of the tangent circle on the perpendicular line to the given line. Similarly, the condition that the tangent circle needed to pass through a given point was achieved by drawing the perpendicular bisector. This type of dynamic exploration led the participants to identify conic sections that were important to solve the tasks. Second, moving or dragging objects within the model became a powerful strategy for the participants to explore and identify what objects attributes or properties changed or were maintained as invariant [26]. In this exploration, finding loci of particular objects (intersection points) was important to formulate conjectures or mathematical relations of the involved objects. Third, the participants recognized that the dynamic models of tasks represent a family of objects since initial parameters (line position, radii of circles, points, etc.) could be changed without modifying the model structure. That is, the model preserves its initial structure and properties. In this context, the dragging affordance was useful to visualize and empirically examine the validity of conjectures and relationships. Fourth, online development (Wikipedia) or apps (Padlet, FaceTime) became important for the participants to consult information regarding concepts involved in the tasks and also to discuss their ideas and approaches to the task beyond the class sessions. Likewise, consulting and reviewing information from online platforms was important for the participants to contextualize the problem situation and to delve into problem solutions.

In summary, the participants in this study showed that the coordinated use of digital technologies shapes both the ways of representing, exploring, and solving mathematical tasks. Online developments and communication apps also played an important role in consulting, reviewing, extending, and sharing ideas and approaches beyond formal settings. It was also shown that the coordinated use of digital technologies provided affordances for them to transform an initial or research problem into a set of learning tasks and activities. Furthermore, teachers' discussions of these problems led them to identify different strategies and solution methods that involve the use of different concepts and mathematical resources.

Finally, we argue that the development of teachers and students' mathematical thinking requires continuous reflection processes and discussions of tasks in which they have diverse opportunities to share and refine their problem-solving approaches. To this end, the use of digital technologies, including online developments or communication apps, and mathematical action technologies, such as GeoGebra, not only becomes important to share and extend mathematical discussion beyond formal settings, but also opens up novel routes for learners to represent and explore mathematical problems.

Author Contributions: Conceptualization, M.S.-T., F.B.-M. and M.C.-M.; methodology, M.S.-T., F.B.M. and M.C.-M.; software, M.S.-T., F.B.-M. and M.C.-M.; validation, M.S.-T., F.B.-M. and M.C.-M.; formal analysis, M.S.-T., F.B.-M. and M.C.-M.; investigation, M.S.-T., F.B.-M. and M.C.-M.; resources, M.S.-T., F.B.-M. and M.C.-M.; data curation, M.S.-T., F.B.-M. and M.C.-M.; writing-original draft preparation, M.S.-T., F.B.-M. and M.C.-M.; writing—review and editing, M.S.-T., F.B.-M. and M.C.M.; visualization, M.S.-T., F.B.-M. and M.C.-M.; supervision, M.S.-T., F.B.-M. and M.C.-M.; project administration, M.S.-T., and M.C.-M.; funding acquisition, M.S.-T. and M.C.-M. All authors have read and agreed to the published version of the manuscript.

Funding: This research was developed within the research projects with references SEP-Cinvestav12 and EDU2017-84276-R financed by the Spanish State Research Agency.

Institutional Review Board Statement: This study did not require ethical approval.

Informed Consent Statement: Informed consent was obtained from all subjects involved in this research. 


\section{Data Availability Statement: Not applicable.}

Acknowledgments: The authors acknowledge the support received from research projects SEPCinvestav12 and Plan Nacional of MICINN of the Spanish State Research Agency, with reference EDU2017-84276-R during the development of this research.

Conflicts of Interest: The authors declare no conflict of interest. The funders had no role in the design of the research; in the collection, analyses or interpretation of data and in the writing of the manuscript or in the decision to publish the results.

\section{References}

1. Törner, G.; Schoenfeld, A.H.; Reiss, K.M. Problem solving around the world: Summing up the state of the art. ZDM Math. Educ. 2007, 39, 353. [CrossRef]

2. Liljedahl, P.; Santos-Trigo, M. (Eds.) Mathematical Problem Solving, Current Themes, Trends, and Research; Springer: Cham, Switzerland, 2019. [CrossRef]

3. Mamona-Downs, J.; Downs, M. The identity of problem solving. J. Math. Behav. 2005, 24, 385-401. [CrossRef]

4. Schoenfeld, A. What makes for powerful classrooms, and how can we support teachers in creating them? A story of research and practice, productively intertwined. Educ. Res. 2014, 43, 404-412. [CrossRef]

5. Schoenfeld, A.H. Mathematical practices, in theory and practice. ZDM Math. Educ. 2020. [CrossRef]

6. Santos-Trigo, M. Problem-solving in mathematics education. In Encyclopedia of Mathematics Education, 2nd ed.; Lerman, S.E., Ed.; Springer: Cham, Switzerland, 2020; pp. 686-693. [CrossRef]

7. Hiebert, J.; Carpenter, T.P.; Fennema, E.; Fuson, K.; Human, P.; Murray, H.; Oliver, A.; Wearne, D. Problem solving as a basis for reform in curriculum and instruction: The case of mathematics. Educ. Res. 1996, 25, 12-21. [CrossRef]

8. Santos-Trigo, M.; Reyes-Martínez, I. High school prospective teachers' problem-solving reasoning that involves the coordinated use of digital technologies. Int. J. Math. Educ. Sci. Technol. 2019, 50, 182-201. [CrossRef]

9. Romberg, T.A.; Kaput, J.J. Mathematics worth teaching, mathematics worth understanding. In Mathematics Classroom that Promote Understanding; Fennema, E., Romberg, T.A., Eds.; Lawrence Erlbaum Associates: Mahwah, NJ, USA, 1999 ; pp. 3-17.

10. Marton, F.; Pang, M.F. On some necessary conditions of learning. J. Learn. Sci. 2006, 15, 193-220. [CrossRef]

11. Hwang, G.-J.; Tu, Y.-F. Roles and Research Trends of Artificial Intelligence in Mathematics Education: A Bibliometric Mapping Analysis and Systematic Review. Mathematics 2021, 9, 584. [CrossRef]

12. Halmos, P. The heart of mathematics. Am. Math. Mon. 1980, 87, 519-524. [CrossRef]

13. Sinclair, N.; Watson, A.; Zazkis, R.; Mason, J. The structuring of personal spaces. J. Math. Behav. 2011, 30, 291-303. [CrossRef]

14. Selden, J.; Mason, A.; Selden, A. Can average calculus students solve nonroutine problems? J. Math. Behav. 1989, 8, 45-50.

15. Santos-Trigo, M.; Camacho-Machín, M. Towards the construction of a framework to deal with routine problems to foster mathematical inquiry. Primus 2009, 19, 260-279. [CrossRef]

16. Mason, J.; Johnston-Wilder, S. Designing and Using Mathematical Tasks; Tarquin Publications: Hertfordshire, UK, 2006.

17. Cho, M.K.; Kim, M.K. Investigating elementary students problem solving and teacher scaffolding in solving an ill-structured problem. Int. J. Educ. Math. Sci. Technol. 2020, 8, 274-289. [CrossRef]

18. Mason, J. Evolution of a task domain. Dig. Exp. Math. Educ. 2019. [CrossRef]

19. Mason, J. Questioning in mathematics education. In Encyclopedia of Mathematics Education; Lerman, S., Ed.; Springer: Dordrecht, The Netherlands, 2014; pp. 513-519.

20. Trouche, L. Managing the complexity of human/machine interactions in computerized learning environments: Guiding students command process through instrumental orchestrations. Int. J. Comput. Math. Learn. 2004, 9, 281-307. [CrossRef]

21. Gravemeijer, K.; Stephan, M.; Julie, C.; Lin, F.-L.; Ohtani, M. What mathematics education may prepare students for the society of the future. Int. J. Sci. Math. Educ. 2017, 15, 105-123. [CrossRef]

22. Hollebrands, K.; Okumus, S. Secondary mathematics teachers' instrumental integration in technology-rich geometry classroom. J. Math. Behav. 2018, 49, 82-94. [CrossRef]

23. Polya, G. How to Solve it; Princeton University: Princeton, NJ, USA, 1945.

24. Santos-Trigo, M.; Moreno-Armella, L.; Camacho-Machín, M. Problem solving and the use of digital technologies within the mathematical working space framework. ZDM Math. Educ. 2016, 48, 827-842. [CrossRef]

25. Santos-Trigo, M.; Aguilar-Magallón, D.; Reyes-Rodríguez, I. A mathematical problem-solving approach based on digital technology affordances to represent, explore, and solve problem via geometric reasoning. In Problem Solving in Mathematics Instruction and Teacher Professional Development; Research in Mathematics Education; Felmer, P., Liljedahl, P., Koichu, B., Eds.; Springer: Cham, Switzerland, 2019; pp. 145-166. [CrossRef]

26. Clark-Wilson, A.; Hoyles, C. A research-informed web-based professional development toolkit to support technology-enhanced mathematics teaching at scale. Educ. Stud. Math. 2018. [CrossRef]

27. Olsson, J. Relations between task design and students' utilization of GeoGebra. Dig. Exp. Math. Educ. 2019, 5, 223-251. [CrossRef]

28. Moreno-Guerrero, A.; Rondón García, M.; Martínez Heredia, N.; Rodríguez-Garcia, A. Collaborative Learning Based on Harry Potter for Learning Geometric Figures in the Subject of Mathematics. Mathematics 2020, 8, 369. [CrossRef] 
29. Koichu, B.; Keller, N. Creating and sustaining online problem solving forums: Two perspectives. In Mathematical Problem Solving, ICME-13 Monographs; Liljedahl, P., Santos-Trigo, M., Eds.; Springer: Cham, Switzerland, 2019; pp. 263-287. [CrossRef]

30. Lincoln, Y.S.; Guba, E.G. Naturalistic Inquiry; SAGE Publications: London, UK, 1985.

31. Santos-Trigo, M.; Barrera-Mora, F. High school teachers' problem-solving activities to review and extend their mathematical and didactical knowledge. Primus 2011, 21, 699-718. [CrossRef]

32. Court, N.A. The problem of Apollonius. Math. Teacher 1961, 54, 444-452.

33. Lesh, R.; Doerr, H.M. Foundations of a models and modeling perspective on mathematics teaching, learning, and problem solving. In Beyond Constructivism, Models and Modeling Perspectives on Mathematics Problem Solving, Learning, and Teaching; Lesh, R., Doerr, H.M., Eds.; Lawrence Erlbaum Associated: Mahwah, NJ, USA, 2003; pp. 3-33.

34. Lesh, R.; Cramer, K.; Doerr, H.M.; Post, T.; Zawojewski, J.S. Model development sequences. In Beyond Constructivism, Models and Modeling Perspectives on Mathematics Problem Solving, Learning, and Teaching; Lesh, R., Doerr, H.M., Eds.; Lawrence Erlbaum Associated: Mahwah, NJ, USA, 2003; pp. 35-58.

35. Weinhandl, R.; Lavicza, Z.; Hohenwarter, M.; Schallert, S. Enhancing flipped mathematics education by utilising GeoGebra. Int. J. Educ. Math. Sci. Technol. 2020, 8, 1-15. [CrossRef]

36. Coxeter, H.S.M. The Problem of Apollonius. Am. Math. Mon. 1968, 75, 5-15. [CrossRef]

37. Del Cerro Velázquez, F.; Morales Méndez, G. Application in Augmented Reality for Learning Mathematical Functions: A Study for the Development of Spatial Intelligence in Secondary Education Students. Mathematics 2021, 9, 369. [CrossRef] 